\title{
La revolución onto-epistemológica del constructivismo en las relaciones internacionales
}

\author{
The onto-epistemological revolution of Constructivism \\ in International Relations
}

JONATHAN ARRIOLA*

\begin{abstract}
Resumen: El constructivismo se ha consolidado como una teoría alternativa a las que ofrecían el realismo y el liberalismo, los cuales, hasta la caída de la URSS, habían dominado la escena teórica de las Relaciones Internacionales (RI). En el siguiente artículo defendemos la idea de que la irrupción del constructivismo implicó una doble innovación a nivel teórico con respecto al resto de las teorías de RI. La primera innovación se da en el nivel ontológico ya que el constructivismo, en contraste con el realismo y el liberalismo, concibe a la realidad social como un ente elástico, esto es, como un objeto conformable por la historia, las instituciones, la voluntad de los actores, etc. Y la segunda a nivel epistemológico, dado que afirma que para comprender esa realidad social, en la que, por supuesto, se circunscriben las RI, es necesario apelar a una desconstrucción hermenéutica, que sea capaz de dar cuenta de la historicidad, de los discursos imperantes y de las ideas que configuran la realidad social. Concluiremos que el constructivismo más que una teoría de las RI propiamente dicha es una "meta-teoría" ya que
\end{abstract}

\begin{abstract}
Constructivism has consolidated itself as one of the alternatives theory to realism and liberalism, which, until the fall of the USSR, had dominated the theoretical landscape of International Relations (IR). In the following article, I will argue that constructivism involved a double innovation at the theoretical level with regard to the rest of the theories of IS. The first innovation takes place at the ontological level, given that constructivism, in contrast to realism and liberalism, conceives of social reality as an elastic entity, that is, as an object conformable by history, institutions, the will of the actors involved, etc. The second one takes place at the epistemological level since constructivism affirms that in order to understand such reality it is necessary to resort to a hermeneutical deconstruction that could account for historicity, the dominant discourses and the ideas that constitute social reality. We conclude by pointing out that constructivism rather than a theory of IR itself is a "meta-theory" insofar as what it proposes is, in essence, an ontology of the rest of the IR
\end{abstract}

Fecha de recepción: 14/07/2014. Fecha de aceptación: 04/03/2015.

* Licenciado en Estudios Internacionales (Universidad ORT Uruguay). Máster en Filosofía Contemporánea (Universidad de la República, Uruguay). Profesor de Política Comparada y Fundamentos de la Investigación Social en la Universidad ORT Uruguay (contacto: jon.arriola@hotmail.com). Líneas de trabajo: filosofía política, pensamiento moderno, filosofía francesa contemporánea. Autor de: «Ilustración y Mito: el origen de la barbarie en Adorno, Horkheimer y Cassirer» (2013) y «Políticas do Extraordinário. Lógicas de transformação em Schmitt e Badiou». (2014). Disponibles en: https://ort-uy.academia.edu/JonathanArriola 
lo que, en el fondo, propone es una ontología del resto de las teorías de RI, mostrando que las mismas son, pese a sus propias aspiraciones, discurso en lugar de ciencia.

Palabras clave: constructivismo, epistemología, ontología, relaciones internacionales, realismo. theories, showing that they are, despite their own aspirations, discourse rather than science.

Keywords: constructivism, epistemology, ontology, international relations, realism

'We construct worlds we know in a world we do not.'

Nicholas Onuf

„Wir leben immer in einer Welt, die wir uns selbst bilden."

Johann G. Herder

\section{Introducción}

\section{a) El auge del constructivismo}

En los últimos años, grosso modo, desde finales de los 80' hasta esta parte, el constructivismo en Relaciones Internacionales (RI) se ha consolidado como una de las alternativas más sólidas a las teorías realista y liberal, en todas sus variantes y sub-géneros ${ }^{1}$, las cuales, desde la Segunda Guerra Mundial, habían ejercido un dominio indiscutido, y aparentemente indiscutible, sobre la reflexión internacionalista.

El World of Our Making (1989) de Nicholas Onuf junto con el Anarchy is What States Make of It (1992) de Alexander Wendt, dos de los textos fundacionales del constructivismo, constituyeron un punto de inflexión en la historia del pensamiento teórico de la disciplina. Y ello porque, ante todo, lo que Onuf y Wendt lograron hacer con sus respectivas propuestas fue romper con el modelo ontológico y epistemológico positivista que tanto el realismo como el liberalismo presuponían, tal vez no del todo conscientes, y en cuyo marco se había desarrollado toda la discusión teórica en RI desde principios de siglo XX. Haciéndose eco de los desarrollos acumulados durante décadas en las áreas de la filosofía, antropología, lingüística y especialmente de la sociología, el constructivismo supuso para la disciplina un cambio de paradigma.

1 Aunque por cuestiones de espacio, es imposible desarrollar aquí en detalle las teorías realista y liberal, sí es posible trazar, al menos, las características fundamentales de ambas. El liberalismo (o idealismo), en su formulación clásica, pone el acento en el deseo de prosperidad y de paz de los Estados democráticos. Cree que las instituciones internacionales, el comercio y la difusión de la democracia son factores que contribuyen a la cooperación y a una gradual eliminación de la guerra como mecanismo de resolución de las controversias. Por su lado, el realismo parte de la premisa que los Estados son actores egoístas que, dada la ausencia de un ente supranacional que regule las relaciones entre ellos, esto es, dada la anarquía estructural, los mismos se encuentran en una situación de competencia continua por el poder y la seguridad que garanticen su supervivencia. Más allá del régimen político, para el realismo, el Estado es un actor racional cuyo principal objetivo es la maximización de su poder, entendido éste como el aumento de sus capacidades económicas y militares principalmente. 
Pergeñado con esa nueva ontología y epistemología, el constructivismo se abrió paso por allí donde el realismo y el liberalismo, y sus respectivas versiones "neo", o bien no habían explorado suficientemente o bien ni siquiera lo habían intentado debido simplemente a un desinterés teórico ${ }^{2}$. De esa forma, el constructivismo cobró un fuerte impulso, explotando virtualmente en la literatura de los años 90. Quizás los ejemplos más destacados de ello sean textos como el National Interests in International Society (1996) de Crawford, el Legitimacy and Power Politics (2002) de Bukovansky, el Revolutions in Sovereignty (2001) de Philpott y el Rethinking the World: Great Power Strategies and International Order (2007) de Legro, entre otros ${ }^{3}$. Conjuntamente con esta frondosa producción intelectual, se redescubrieron viejos problemas que acuciaban a la disciplina, como, por ejemplo, los ligados al papel de la contingencia histórica en la conformación de la estructura internacional. Al mismo tiempo, se arrojó luz sobre otras problemáticas que habían carecido de un tratamiento adecuado bajo el enfoque estructuralista, positivista y transhistórico ${ }^{4}$ de las teorías liberal y realista, tales como los del origen, significación y legitimación del concepto de soberanía.

Ahora bien, dado los múltiples desarrollos que ha tenido recientemente, no sería preciso hablar de "el" constructivismo como si fuera una corriente única, internamente consistente. Dentro del mismo existen, como en el caso del realismo y liberalismo, distintos acentos y enfoques que pautan diferencias tanto en las líneas de investigación como en las teóricas. De hecho, es porque los desarrollos del constructivismo fueron tan rápidos como dispares, que, como bien retrata Stefano Guizzini en su "Reconstruction of Constructivism in International Relations" (2000), algunos autores, como Adler, Checkel, Hopf y también él mismo, se han empeñado en la tarea de reconstruir, con vocación sistematizadora, la coherencia interna del movimiento, amenazada, en algún punto, por la avalancha de artículos de eclécticas perspectivas que aparecieron en los últimos años. ${ }^{5}$

Las razones para este particular auge del constructivismo son varias. Sin embargo, a grandes rasgos las podemos dividir en dos: por un lado, las exógenas, es decir, las que provienen por fuera de la reflexión teórica propiamente dicha y, por otro, las endógenas, a saber, las que surgen de un desarrollo interno tanto del pensamiento internacional mismo o de disciplinas aledañas. Comencemos por las primeras.

2 Ejemplos de esas áreas enteras olvidadas por estas teorías, eran el estudio hermenéutico de la historia y la definición del papel de la identidad cultural, del discurso y de la intersubjetividad en la construcción del sistema internacional.

3 Christian Reus-Smit, en su Leyendo la historia con una mirada constructivista (2002) pág. 65, hace una enumeración exhaustiva de los trabajos de corte constructivista que aparecieron a partir de 1989.

4 Para ver una discusión más profunda sobre el carácter transhistórico de las teorías realista en contraposición con el carácter contingente del constructivismo, ver el artículo de Samuel Barkin Realism, Constructivism, and International Relations Theory (2009).

5 En efecto, Guizzini apunta muy bien la problemática a la que hacemos referencia: "The sheer diversity seems to make the category of constructivism explode. Consequently, the plethora of recent survey articles decided to give constructivism a better coherence either by emphasizing a single particular view (Adler, 1997), by picking out particular approaches for discussion (Checkel, 1998) or by providing typologies (Hopf, 1998)." (2000: 148-149) 


\section{b) Caída de la URSS y sus implicaciones teóricas}

Uno de los factores exógenos que más coadyuvó a la envión constructivista de los años 90' fue, sin dudas, la inesperada caída del muro de Berlin y el subsiguiente derrumbe de la URSS. El motivo por el cual estos acontecimientos fertilizaron el terreno para el constructivismo es muy sencillo: los mismos marcaban el fin de la Guerra Fría, y significaban el final del marco histórico-estructural que había amparado la emergencia de varias teorías de RI, sobre todo, del neorrealismo de Waltz y del neoliberalismo de Keohane y Nye, que habían ejercido un predominio casi monopólico. En general despreocupadas por comprender los cambios sistémicos, puesto que éstos, aducían, eran excepcionales, ambas teorías [neorrealista y neoliberal] se vieron totalmente sorprendidas por los rápidos sucesos históricos que desencadenaron el final del comunismo y de una bipolaridad que se daba por sentada. Dichos cambios no pudieron ser explicados por unas teorías de prosapia positivista y estructuralista preocupadas fundamentalmente por obtener leyes naturales objetivas y eternas del sistema internacional, dejando de lado las contingencias históricas, a las que en general presentaban como accesorias ${ }^{6}$.

Pero, por su magnitud para el sistema internacional en su conjunto, el desplome de la Unión Soviética y, como consecuencia, de toda la estructura político-ideológica que se había montado sobre ella, no podía ser un episodio teóricamente marginalizable: convocaba a una reflexión profunda no sólo sobre la naturaleza del sistema internacional sino también sobre la validez de los enfoques teóricos utilizados para abordarla hasta ese momento. Y es que, ante todo, la debacle soviética trajo al centro de la escena lo que el realismo y el liberalismo habían hecho a un costado: en primer lugar, la ineludible importancia de la historia a la hora de entender los desarrollos de las RI y, en segundo lugar, la necesidad de elaborar una teoría que efectivamente pensara los cambios estructurales no como meras excepciones o disrupciones sino como momentos fundantes.

Aunque el realismo contaba con un herramental teórico que podía dar cuenta del funcionamiento de la estructura internacional, estaba huérfano de una reflexión metafísica sobre la naturaleza de ésa estructura: a saber, su origen histórico, sus despliegues internos y su temporalidad. Tenía una teoría sobre qué patrones regían las interacciones al interior de la estructura pero carecía de una teoría que explicase el comportamiento de la estructura misma. Se asumía que estaba "dada".

Sin embargo, ¿cómo era posible explicar la Perestroika y la Glásnost de Gorvachov desde el paradigma realista que asumía sin más la existencia a priori de una estructura determinada? Con la caída de la URSS, hubo que reconocer que el mundo internacional era definitivamente más complejo de lo que presuponía el realismo, cuya larga hegemonía teórica en la disciplina comenzaba a ser rápidamente socavada. En general, los realistas se vieron obligados a aceptar que en la estructura internacional existen algunos "puntos

6 Un ejemplo de episodio catalogado de "secundario" fue el de la guerra de Vietnam. Desde el paradigma realista, resultaba difícil entender por qué los EE.UU. decidían retirarse derrotados del país asiático cuando su interés nacional al iniciar la guerra era exactamente el mismo que al terminarla. No hace falta decir que la "opinión pública" tuvo mucho que ver con esa decisión pero el realismo no la había incorporado como un factor de peso en el comportamiento de los actores y en la definición de su "interés nacional". 
de fuga" por donde su teoría falla. Dicho directamente: el realismo funcionaba bien en la normalidad pero no en la excepción.

El fin del mundo bipolar reveló que no bastaba sólo con "medir" el poder nacional, definido generalmente en términos materiales (poder militar, económico, etc.), identificar la posición de los actores (Estados) en el sistema y, a partir de allí, derivar, como en un silogismo, unos intereses nacionales que aparentemente estarían abstraídos del espacio y del tiempo. Tampoco satisfacían los intentos, para finales de los años 90', más cosméticos que sustantivos, emprendidos por el realismo neoclásico de autores como Rose, Aferro y Labell $^{7}$, que buscaron matizar el materialismo el enfoque metodológico holista del realismo original, al señalar respectivamente la importancia del marco ideológico y de las elites en la toma de decisiones. El problema con estos intentos de revitalización del realismo fue que en lo esencial mantenían el mecanicismo tosco sobre el cual éste había fundamentado su abordaje teórico de tipo estructuralista. Y era precisamente ése mecanicismo lo que había que reformular de forma urgente.

Entiéndase bien, no se trataba de abandonar completamente el estructuralismo, si bien eso fue lo que propusieron, en general, las teorías posmodernas, sino de señalar sus carencias y limitaciones teóricas. En ese sentido, podemos decir que luego de la caída de la cortina de hierro, se convino en señalar que una teoría materialista del sistema internacional era condición necesaria pero no suficiente para explicar la complejidad de las RI. Lacónicamente: había que conservar el estructuralismo pero al mismo tiempo había que superarlo, poniéndolo en nuevos términos. Y fue precisamente esa labor "dialéctica" la que llevó a cabo el constructivismo al conjugar el enfoque estructuralista con una perspectiva "ideacionista" , que destaca la importancia de la intersubjetividad, las ideas y la historicidad en la conformación de cualquier estructura social, sea nacional o internacional.

Con esta perspectiva teórica novedosa, el constructivismo se abrió paso rápidamente en los círculos académicos. Especialmente atractivo era el hecho de que su propuesta evitaba caer tanto en los excesos del materialismo como en los del idealismo, logrando conquistar así el llamado middle ground entre las teorías realista y liberal, que había estado vacante durante mucho tiempo y que el post-estructuralismo posmoderno no supo capitalizar 9 .

\section{c) El agotamiento del positivismo}

Pero no sólo el abrupto final de la Guerra Fría desbrozó el camino para el constructivismo. Como ya señalábamos, también hubo agotamientos y desarrollos conceptuales y epistemológicos, tanto a nivel de las ciencias sociales como de la filosofía, que llamaron a replantear el problema de las RI por fuera de la ya vetusta dicotomía realismo versus liberalismo.

7 Los textos más importantes de estos autores que propiciaron el surgimiento del realismo neoclásico son: Neoclasical Realism and Theories of Foreign Policy (1998) Jeffrey Tali Aferro, Neoclasical Realism and Extraction: State Building (2009) y Threat Assesment, the State and Foreign Policy (2009) de Steven E. Labell.

8 Decimos "ideacionista" para evitar la confusión con el concepto de "idealista", cuyo significado reenvía definitivamente al territorio de la normatividad.

9 GUZZINI, Stefano. A Reconstruction of Constructivism in International Relations. En: European Journal of International Relations 2000. CA and New Delhi, Vol. 6(2): 147. 
Uno de los procesos más importantes que incidieron en la conformación del constructivismo, fue el progresivo debilitamiento del positivismo para los años 70' y 80', el cual había funcionado como base epistemológica del realismo y, aunque en menor medida, también del liberalismo. Hay que apuntar aquí que ese agotamiento no se constató solamente en el ámbito específico de las RI sino que afectó más ampliamente a todas las ciencias sociales y aún más allá. El autor constructivista Nicholas Onuf, en su texto The Strange Career of Constructivism in International Relations (2002), describe muy bien el ambiente intelectual de esos años cuando se comenzó a sospechar y, más aún, a cuestionar abiertamente los fundamentos de la ciencia positivista. Así señala:

"Scholars have always raised questions about accepted ways of seeing. Beginning
in the 1970 s, their numbers increased, in the 1980s dramatically. Some critics came
to the radical conclusion that we know not what we see, and delude ourselves into
thinking that we do. A few others began to see worlds as never-ending construction
projects involving even themselves as agents, and realized that they needed new and
different tools - tools for making worlds and not just for seeing them." (Onuf, 2002).

Lo que estaba teniendo lugar era una auténtica revolución epistemológica acaecida en el seno mismo del pensamiento occidental, que no pudo menos que repercutir en el abordaje científico de las $\mathrm{RI}^{10}$. Es que nos encontramos en los albores de la posmodernidad y, por lo tanto, se advierte ya un profundo desgaste de los llamados meta-relatos típicos del mundo moderno "pre-Einstein", "pre-Saussure" y "pre-Freud", que, como señala Lyotard en su La condición posmoderna (1979), habían apuntalado el desarrollo de la ciencia moderna: el más importante de ellos, el del "progreso".

En efecto, es por entonces que el binomio indisociable ciencia-progreso, sobre el cual la Ilustración había montado un proyecto civilizatorio de una ética, una política y, en fin, de una sociedad "científica", comenzó a resquebrajarse. Los Bachelard y los Kuhn, en la estela de la revolución de Einstein, y luego los Lakatos y los Feyerabend dejaron en claro que el progreso en materia de conocimiento era decididamente más complicado que simplemente acumular y avanzar linealmente, como habían previsto y deseado, aunque ciertamente con reparos y matices, Turgot y Condorcet, junto a otros lumières del siglo XVIII.

Por otro lado, también se suscitaron en el campo de la antropología, de la sociología, de la lingüística y de la semiótica varias coupures épistémologiques cuyo resultado más significativo, siendo esquemáticos, fue el de hacer patentes las carencias del estructuralismo en la comprensión de la realidad social. Pero lo importante a destacar, a los efectos de este trabajo, de estas "revoluciones" es que todas ellas convergieron, principalmente para los 70', en que muchas de las asunciones de la ciencia positivista ${ }^{11}$ resultaban, en realidad, insos-

10 A ese respecto, es oportuno recordar que ya para el final del 60' se constata un "revitalización" de la epistemología, sobre todo a partir del llamado "problema de Gettier", que puso en jaque a la definición tradicional de conocimiento como una "creencia, verdadera y justificada" e inspirase nuevas y numerosas investigaciones.

11 En efecto, "Already in the 1970s, positivists showed signs of fatigue brought on by the demands of normal science. Fatigue made it all the more difficult to cope with dwindling resources as the Vietnam War came to an end, and fatigue did nothing to dull the disappointments due to the meager results that normal science had posted." (Onuf, 2002) 
tenibles a la luz de los nuevos desarrollos conceptuales. En particular, la idea de que era posible acceder transparentemente a la naturaleza de las cosas y de que era posible estudiar la sociedad de la misma manera que cualquier otro "hecho natural", como pretendía Durkheim en la misma dirección que Marx y Comte, pasó a ser concebida más como la expresión de una aspiración epistemológica que una posibilidad real sobre la cual fundamentar el conocimiento científico.

En efecto, el acceso a la objetividad, a la realidad misma de la "cosa en sî" para decirlo con Kant, a la que habían aspirado tanto el positivismo como el neopositivismo se transformó casi que en una quimera ya que, en la envión de los desarrollos científicos del siglo $\mathrm{XX}$, decantó la idea de que todo conocimiento de la Naturaleza presupone siempre al hombre no sólo como observador pasivo de ella sino como constructor activo de ése objeto al que se enfrenta. En otras palabras: el nuevo paradigma epistemológico afirmaba que no hay fenómeno sin sujeto puesto que el segundo es la condición de posibilidad del primero. Por lo tanto, no se lo puede expulsar en favor de la obtención de una "objetividad pura", lo que implica aceptar que, en lugar de tener conocimiento de la realidad misma, obtenemos de ella una imagen. Y ello, amén de Kant, ya lo había visto Heisenberg ${ }^{12}$ para la física de los años 30', cuánto más válido era para las ciencias sociales de los años 70'.

De esa forma, se comenzó a trabajar sobre la concepción de que tanto el objeto "sociedad" como su conocimiento eran en verdad una construccion, más que algo simplemente "dado" a los sentidos. Quizás la corriente que más haya trabajado con esta concepción, sobre todo con la idea de que la sociedad es una suerte de artefacto, fue la ecléctica ${ }^{13}$ Escuela Inglesa de RI, que tomó renovados impulsos con las obras de Wight, Bull, Vigezzi y Dunne, entre otros, a partir de los años 80'. Por ese carril, la Escuela Inglesa abandonaba el crudo cientificismo del positivismo, del que el realismo era claro portador, que ignoraba raudamente la especificidad ontológica de la esfera humana además de hipostasiar las RI al equiparlas con el resto de los hechos del mundo natural. Para esta nueva corriente de pensamiento de RI, que está encaminada ya en la dirección del constructivismo, la anarquía del sistema internacional no es una estructura que, por sí misma, determine automáticamente una situación de self-help por parte de los Estados, como describe Waltz. En la versión de la Escuela inglesa, los mismos no se comportan solamente en base al principio hiper-racionalista de "costo-beneficio" sino que comparten con otros Estados intereses comunes y, en virtud de ellos, pueden, como había imaginado el contractualismo, decidir establecer normas e instituciones que regulen las interacciones. De esa forma, les es otorgada a los Estados la potestad de convertir esa anarquía estructural dada en algo diferente que un sistema en donde sólo se pueda practicar un egoísmo feudal.

Por otro lado, por esos años se asiste también a la emergencia del concepto de identidad tanto en sociología, en filosofía como en ciencia política, que trajo aparejado un renovado interés por el estudio de la cultura, propio de las teorías posmarxistas. A ello se sumó luego la ya mencionada caída del comunismo, lo que despertó una preocupación por las identidades nacionales que habían sido largamente ensombrecidas por el bicromatismo de la Guerra Fría.

12 El texto en donde expone esa tesis es La imagen de la Naturaleza en la física actual (1955).

13 Decimos ecléctico porque la Escuela inglesa tiene influencias y afinidades conceptuales con diversas teorías de relaciones internacionales, tales como el realismo clásico, el neorrealismo, las teorías críticas, el posestructuralismo además de los influjos grociano y kantiano. 
Además de otros autores, quizás haya sido Bourdieu, uno de los sociólogos más influyentes, el primero en dedicar un lugar privilegiado en su reflexión al tema de la identidad y del multiculturalismo ${ }^{14}$-recuérdese, simplemente, a título de ejemplo, su L'identité et la représentation (1980) - . En este punto, hay que decir que Bourdieu no descarta el estructuralismo: lo que hace es historizarlo y dotarlo de una dimensión subjetiva, al concebir a las estructuras sociales, no como un fenómeno natural de orden objetivo sino como producto de una historia colectiva, tejida constantemente por las prácticas sociales y, por lo tanto, no determinada de antemano por algún proceso lineal o mecánico. De esa manera, Bourdieu no sólo le imprime a la idea de estructura un nuevo significado sino que lo hace de tal modo que, al mismo tiempo, logra también recuperar, por la vía de rescatar la intersubjetividad, la importancia de la agencia en la definición y conformación de cualquier estructura.

Por otro lado, el concepto de identidad también se volvió fundamental para atacar las teorías de la elección racional, que eran la consecuencia natural del modelo positivista de ciencia. Dichas teorías, aún para finales de los 70' gozaban de buena salud - de hecho, el Theory of International Politics (1979) de Waltz es un ejemplo de esa metodología - y permitieron fundamentar lo que se dio en llamar el "twinning" del neorrealismo y del neoliberalismo de los años 80' (Baldwin, 1993). Los modelos matemáticos y la formalización pasaron a dominar la escena, $y$, en algunos círculos académicos, hasta el día de hoy. Pero las ciencias sociales, poco a poco, se despegaron de este modelo y, en su lugar, señalaron que los intereses, sean éstos individuales o colectivos, no están simplemente dados a priori por ocupar un determinado lugar o función en la estructura sino que se configuran de forma relativamente libre en el incesante juego de las subjetividades.

Demás está decir que todas estas innovaciones conceptuales y metodológicas que mencionamos serán cristalizadas en la teoría constructivista, en lo que Onuf llama el constructivistic turn y, en particular, por los textos de Wendt que, en general, estarán fuertemente impregnados por una tónica sociológica.

\section{La revolución onto-epistemológica del constructivismo}

Hasta aquí nos hemos remitido a señalar tan sólo algunas de las condiciones exógenas y endógenas que propiciaron la emergencia de la teoría constructivista en las RI. Ahora bien, en vista de ello, es válido preguntarse cuáles son efectivamente los aportes específicos del constructivismo al análisis de las RI que constituyen una renovación de la disciplina. Algunos de ellos ya los hemos adelantado. Pero quizás el aporte más importante sea lo que llamaremos su revolución "onto-epistemológica". Utilizamos ese término porque el constructivismo supuso ciertamente una doble innovación: tanto a nivel ontológico, a saber, a nivel de su concepción de cómo es la realidad (social), como a nivel epistemológico, esto es, a nivel de si se puede o no conocer esa realidad y, en caso afirmativo, de qué manera.

14 "In democratic theory, this shows up in the discussions about multicultural societies (Taylor, 1992; Kymlicka, 1995). More generally, it reverberates in the debates about the social construction of collective identities in the form of Imagined Communities (Anderson, 1991), and our construction of others, like Edward Said's (1979) Orientalism. In International Relations, poststructuralists deconstructed the practice of sovereignty as the historical solution to the problem of cultural pluralism and universalism." (Guzzini, 2000: 154) 
a) Ontología

La revolución ontológica más importante del constructivismo con respecto a las teorías predominantes hasta su aparición es, como hemos mencionado, el reconocimiento expreso de que la realidad social no es sino una construcción intersubjetiva. El realismo y, en menor medida, el liberalismo funcionaban sobre la base de una ontología realista, prohijada del positivismo, según la cual la estructura de la realidad era de pleno accesible por los sentidos y fácilmente asible por la conciencia, método científico mediante. No obstante, el constructivismo rechaza esa concepción objetivista de la realidad por considerarla ontológicamente más compleja.

Pero entiéndase bien: que el constructivismo crea que el mundo social no está dotado de una objetividad maciza y transhistórica sino que es configurado por prácticas sociales e ideas no quiere decir que el mismo incurra en una suerte de "idealismo absoluto" que no reconozca nada más allá de los propios contenidos mentales o de las propias prácticas sociales. Si el mundo internacional del realismo y del liberalismo era uno donde las condiciones materiales se imponían indefectiblemente a los Estados, al punto que el mundo social era concebido casi que un mero reflejo del mundo material, el mundo internacional del constructivismo es principalmente uno en donde el mundo de lo social ejerce la predominancia. En esas concepciones, que muestran una preferencia o bien por el mundo material o bien por el mundo social, se vislumbra aquella decisión ontológica que distingue al constructivismo de las demás teorías de las RI.

En este punto, es preciso aclarar que la revolución constructivista no consiste en negar la importancia de la materialidad y de sus evidentes constricciones, mucho menos en negar la existencia de un mundo exterior independiente de toda construcción social. El constructivismo no es un solipsismo. La revolución consiste, más bien, en señalar que esa materialidad no determina linealmente el comportamiento de los Estados y/o de los demás actores internacionales. Con ello queremos decir que, ante todo, el constructivismo apunta a dejar de pensar el funcionamiento de la realidad social en los rígidos términos de causa y efecto, de estímulo y respuesta, como había hecho hasta entonces el positivismo y, por extensión, el realismo, ya que dicho modelo "cerrado" admitía algún excurso. Puesto de otra manera: el constructivismo quiere romper con el determinismo ontológico del realismo porque el mismo es incapaz de hacer espacio a la idea de libertad de los actores. En efecto, el constructivismo argumenta que así como existe una estructura material que constriñe a los actores a tomar determinadas rutas de acción así también existe una estructura ideacional, formada por prácticas sociales y los discursos, que son libres y espontáneos, y que, con la historia, otorgan una determinada identidad a los Estados, enmarcando así sus posibilidades de acción.

En ese senitdo, el constructivismo es a la vez idealista e ideacionista. Idealista en el sentido que cree que la conciencia coparticipa activamente en el conocimiento del mundo y que es imposible una tajante distinción ontológica entre mente y mundo, concepto y realidad. E ideacionista porque cree que la influencia de las ideas es tan o más importante para comprender la estructura internacional y sus desarrollos históricos que la materialidad pura y dura, como defendían, a grandes rasgos, el realismo y el liberalismo, pasando por alto la, y permítasenos el término heideggeriano, "diferencia ontológica" que, según el constructivismo, existe entre el mundo natural y el mundo social. 
En última instancia, estas diferencias enraízan en una concepción distinta de la naturaleza humana, que está en la base, más o menos explícitamente, de todas las teorías de RI. Precisamente, mientras el realismo opera con una imagen del hombre que pone el acento en sus dimensiones biológica y racional, el constructivismo, adoptando una postura existencialista, es reticente a afirmarse en una concepción esencialista de la naturaleza humana. Y ello por la sencilla razón de que cree que el hombre no está, ontológicamente hablando, determinado $a$ priori por ninguna esencia que lo anteceda sino que postula que es él mismo quien se forja libremente una identidad a través de sus proyectos (existenciarios) y, en especial, a través de los proyectos intersubjetivos que emprende. En ese sentido, el constructivismo es claramente afín a aquella sentencia sartreana de que la "existencia precede a la esencia".

Ahora bien, aunque para la realización de sus proyectos, el hombre es libre, no lo es enteramente. De nuevo, el constructivismo evita caer en los extremos: a saber, no es un voluntarismo, no afirma la libertad absoluta del concepto sobre el mundo. En efecto, reconoce que esos proyectos están acotados por las estructuras materiales y/o intersubjetivas dadas de antemano, reificadas por la historia, y que los actores no tienen más remedio que aceptar. Claro que aceptar no es lo mismo que someterse pasivamente: significa, más bien, que será a partir de ésa plataforma ya constituida que los actores podrán desplegar sus posibilidades existenciales.

Obviamente que esto que es válido para el individuo, lo es también para los Estados, a los cuales el constructivismo toma como las unidades (culturales) esenciales, base del sistema internacional ${ }^{15}$. Ciertamente, la anarquía estructural, las instituciones internacionales, los discursos hegemónicos y la distribución del poder constituyen el tejido de condicionantes materiales e ideales que simplemente se imponen. No obstante, para el constructivismo, los Estados tienen un margen de libertad para transformar esa realidad que viene dada en algo nuevo; claro que siempre manteniéndose dentro de las constricciones que ese punto de partida ha establecido irremediablemente. Pongámoslo de otro modo: si el realismo había imaginado una estructura objetiva y, por ende, rígida y fija, de la cual el comportamiento de los Estados no eran sino una simple correa de transmisión, el constructivismo imagina una estructura plástica e histórica, que puede ser modelada por la libertad de los actores en sus interacciones.

Desde el punto de vista ontológico, para el constructivismo, la anarquía política estructural del sistema internacional en sí misma, no significa nada y, en consecuencia, no puede determinar nada para los actores que se encuentren circunscriptos en ella, como piensa el realismo. Es que, para los constructivistas, hasta antes de pasar por el tamiz de la intersubjetividad, de la representación discursiva y de la construcción imaginaria, la anarquía simplemente "es": está, desde el punto de vista normativo y/o simbólico, completamente vacía. Solamente en la medida en que esa estructura conceptualmente desnuda se haga depositaria de algún tipo de contenido semántico o ideacional es que podrá entrar en el mundo de los significados y cobrar así relevancia para los actores que en ella se muevan. Mientras ello no suceda y permanezca ontológicamente indeterminada, la anarquía es sólo una potencialidad. Únicamente a través de los contenidos simbólicos generados a partir de la intersubjetividad

15 Y eso más allá de que, desde el punto de vista metodológico, el mismo sea proclive, al igual el neoliberalismo y el neorrealismo, a estudiar las elites. 
podrá imprimírsele a esa estructura objetiva un ethos particular. De allí precisamente el famoso adagio de Wendt, otra vez de fuerte reminiscencias sartreanas ${ }^{16}$, en donde afirma que la "anarquía es lo que los Estados hacen de ella". Con ello, el autor no hace sino subrayar la elasticidad intrínseca de todo lo que el realismo y el liberalismo, atrincherados en el paradigma objetivista del positivismo, habían tenido por "dado" y "vinculante".

En realidad, hay que decir que esta concepción ontológica del constructivismo, tanto en su versión sociológica como internacionalista, no es radicalmente nueva. Aunque no lo señalen expresamente, es notorio que, como ya adelantamos, el constructivismo tiene claras resonancias kantianas pues su propuesta no trabaja con noúmenos, esto es, con realidades "a secas" a las que se puede acceder límpidamente, sino con fenómenos, es decir, con hechos procesados por las matrices conceptuales y categoriales de la consciencia, por los aparatos de percepción sensorial, llámense los sentidos y principalmente por las construcciones sociales y culturales, en las que se incluyen tanto las discursivas, las imaginarias, las simbólicas como las históricas. En otras palabras: para el constructivismo, desde el punto de vista ontológico, no hay hechos "desnudos" - o más bien estos serían inaccesibles además de irrelevantes para su teoría - solamente representaciones de esos hechos y a ellas es a lo máximo a lo que se puede aspirar, epistemológicamente hablando. De esa forma, esta corriente logra trazar una línea entre lo que es el objeto en sí y lo que es el objeto de conocimiento, el cual se torna inteligible en la medida en que se exponga en el marco de las prácticas culturales.

\section{b) Epistemología}

Amparado en esa ontología que venimos de describir, el ejercicio constructivista par excellence consiste en desmontar esas determinaciones que se consideran producto de la estructura material y descubrir detrás de ellas lo que éstas tienen de construcción social. Así opera, por ejemplo, con el concepto de self-help, el cual, según el realismo, se deriva directamente de la situación de anarquía. Sin embargo, lo que el realismo ve como una realidad que no podría ser de otra manera en virtud de la estructura objetiva imperante, para el constructivismo no es sino, y como repite Wendt, una mera institución, forjada históricamente a partir de las interacciones y convenciones intersubjetivas contingentes. Pero que el realismo confunda lo que es una creación social artificial con una determinación material (la anarquía estructural) no le resulta extraño al constructivismo. Y ello porque la repetición de ciertas prácticas sociales lo que hacen es afirmar y reafirmar las instituciones artificiales que configuran el mundo social hasta el punto de reificarlas y generar el espejismo de ser

16 Lo decimos por el famoso apotegma de Sartre "el hombre es lo que hace con lo que hicieron de él." Por otro lado, en el constructivismo se deja entrever también, y valga el excurso, una influencia indirecta y lejana del filósofo Johann G. Herder. A propósito, recomendamos ver el excelente artículo titulado Johann Gottfried Herder disponible en la página de Stanford: http://plato.stanford.edu/entries/herder/.

En efecto, este filósofo alemán, reaccionando contra el cientificismo de la Ilustración, se convertiría en el padre de la hermenéutica, del historicismo y de los abordajes lingüísticos, concepciones epistemológicas y metodológicas que constituyen el patrimonio teórico lejano del constructivismo. Precisamente, en el acápite de este trabajo intenta poner de relieve que fue Herder de los primeros en visualizar al mundo social como una construcción subjetiva más que como otro ente natural, impulsando lo que se convertiría luego en las Geisteswissenschaften en contraposición a las Naturwissenschaften. 
realidades naturales. Es justamente por esa vía de la repetición que la techné y el nomos se camuflan de physis, engañando, para el constructivismo, tanto la ontología como la epistemología del realismo y liberalismo.

En este punto, no se puede dejar de notar que la crítica constructivista a las teorías clásicas de RI es verdaderamente demoledora pues allí donde éstas dicen lidiar con estructuras de la realidad en sí, el constructivismo no ve sino el reflejo de los contenidos proyectados por los acuerdos intersubjetivos. Peor aún, el realismo principalmente había creído que era posible estudiar las RI situándose en un plano exterior a ella. Su modelo era el modelo del observador no observado. Sin embargo, el constructivismo acusa al realismo de haberse constituido él mismo en uno de esos mecanismos reproductores de las prácticas sociales reificantes. En particular, el realismo habría servido para apuntalar ideológicamente a los conceptos de soberanía e interés nacional, que son el fundamento de las RI actuales.

Visto de ese modo, para el constructivismo, si hasta ahora el realismo ha sido efectivo en la descripción de las RI no es porque, como alega, haya tenido un acceso privilegiado, a una hipotética estructura objetiva de la realidad sino porque su discurso se ha vuelto precisamente el discurso hegemónico y, por medio de él, ha terminado por imponer, de manera subrepticia, el esquema determinista que según aducen los autores realistas sólo estarían extrayendo y/o describiendo de la realidad. En ese sentido, el realismo, muy a pesar de su pretendida vocación científica, tendría una fuerte faceta teleológica, en la medida en que sería el paladín (inconsciente) de una determinada estructura ideacional, que gobernaría el desarrollo de las RI tanto como la estructura anárquica. Lo que sucede es que para el constructivismo, la teoría realista no es, como pretende ser, un conjunto de enunciados constatativos, meras proposiciones analíticas, sino de enunciados performativos. ${ }^{17}$

Y allí yace justamente otra de las grandes "rupturas" onto-epistemológicas del constructivismo. Mientras el neorrealismo y el neoliberalismo, y en especial el primero, apuntaban a producir teorías libres de todo contenido normativo, esto es, teorías puramente descriptivas, el constructivismo descarta de plano esa aspiración. Dada su epistemología, digamos "pospositivista", el constructivismo asegura que, en el caso del mundo social, la realidad se hace, esto es, se construye al tiempo que se enuncia. Ante sus ojos, tener otra pretensión es ignorar alegremente la particularidad ontológica de la esfera humana. Allí no ejercen soberanía sólo las leyes naturales sino también los valores, los significados y, sobre todo, el sentido. Por eso, desde el punto de vista de la explicación científica, es inapropiado quedarse solamente en el nivel de la observación, válido para las ciencias naturales, como hicieron el realismo y el liberalismo. Si se ha de entender plenamente la realidad internacional, es necesario pasar el plano de la acción. En efecto, el mundo social no es un conjunto de cadenas causales, empíricamente determinadas, sino más bien un conjunto de acciones intencionales, que operan en el marco de inteligibilidad dado por el significado y el sentido.

Es por lo anterior que, en última instancia, para el constructivismo, de las RI no obtendremos conocimiento, al menos no en el sentido que le dan las ciencias duras, sino solamente interpretaciones. Por lo tanto, en cuanto a su metodología, el constructivismo opta principalmente por la hermenéutica, que es el arte de la interpretación, de develar el

17 Este de recordar que esta célebre distinción entre enunciados constatativos y enunciativos performativos fue trazada por el filosofó británico John Langshaw Austin en su famoso How to Do Things with Words (1962). 
significado y de dilucidar el sentido. A su vez, el constructivismo es consciente de que esas interpretaciones, en tanto parte integrante del mundo social al que intentan comprender, afectarán inexorablemente a la realidad interpretada. Como consecuencia de lo anterior, el constructivismo logra visualizarse a sí mismo como el agente social que es. Y probablemente sea esa auto-consciencia de la que es portador, la diferencia específica más importante que tiene esta corriente de pensamiento en relación al resto de las teorías.

Esto último que acabamos de decir reenvía a otro problema quizás más esencial: a saber, el de cuál es el estatuto teórico del constructivismo. Más concretamente, el constructivismo ¿es una teoría, un paradigma o simplemente una epistemología? Aquí somos de la opinión de que, en realidad, el constructivismo no es una teoría en el sentido clásico del término pues no es un conjunto de proposiciones acerca de cómo las cosas son. Más bien, el constructivismo parece ser una meta-teoría ya que, en el fondo, lo que propone es fundamentalmente una ontología de las teorías de RI. Precisamente, lo que hace el constructivismo es señalar que no sólo hablamos del ser sino que el ser, entendido como realidad social, es más bien el efecto del decir. Es así que logra aportar un espacio de auto-consciencia removiendo el positivismo objetivizante de las teorías realista y liberal, revelándolas a sí mismas esencialmente como discurso más que como ciencia, en el sentido duro del término. A la luz de la ontología constructivista, más que teorías descriptivas, tanto el realismo como el liberalismo serían indefectiblemente teorías normativas porque, en principio, las RI no son en sí mismas ni realistas ni liberales sino que, dada su indeterminación esencial, pueden serlo, dependiendo del discurso y las prácticas sociales.

Por otro lado, con su epistemología, el constructivismo también logra que las hipostasis, producto de la repetición de ciertas instituciones, prácticas y discursos se muestren justamente como eso que son: formas sociales reificadas a las que hay que desesencializar a través del ejercicio hermenéutico. Ante todo, el constructivismo constituye un recordatorio de que, más allá de las estructuras, de las imposiciones y constricciones objetivas e intersubjetivas, las RI, como el resto de la realidad social, pueden ser lo que los actores quieran que sea. Y he ahí el núcleo duro de su revolución onto-epistemológica.

\section{Bibliografía}

Barkin, Samuel. Realism, Constructivism, and International Relations Theory. En: American Political Science. Association, Toronto, Canada, September 3, 2009.

Braspenning, Thierry. Constructivisme et réflexivisme en théorie des relations internationales. En: AFRI (Annuaire Français de Relations Internationales) Volume III - 1er Janvier 2003. pp. 314-329. Disponible en Internet: http://www.diplomatie.gouv.fr/fr/IMG/pdf/ FD001435.pdf

Guzzini, Stefano. A Reconstruction of Constructivism in International Relations. En: European Journal of International Relations 2000 SAGE Publications, London, Thousand Oaks, CA and New Delhi, Vol. 6(2): 147-182.

Hopf, Ted. The Promise of Constructivism in International Relations Theory. Source: International Security, Vol. 23, No. 1 (Summer, 1998), pp. 171-200. Disponible en Internet: http://www.jstor.org/discover/10.2307/2539267?uid=3737664\&uid=2\&uid=4 \&sid=21102536689857 
Klotz, Audie; Lynch, Cecelia. Le constructivisme dans la théorie des relations internationales. En: Critique Internationale №2 - hiver 1999 pp. 51-62.

Nugroho, Ganjar. Constructivism and International Relations Theories. En: Global \& Strategis, Th. II, No. 1, Januari -Juni 2008, hlm. pp. 85-98.

Onuf, Nicholas. The Strange Career of Constructivism in International Relations. En: "Constructivist IR Research" Center of International Studies, University of Southern California, October 6, 2001.

Reill Hanns, Peter. Science and the Construction of the Cultural Sciences in Late Enlightenment Germany: The Case of Wilhelm von Humboldt. En: History and Theory, Vol. 33. $\mathrm{N}^{\circ} 3$ (Oct. 1994), pp. 345-366.

Reus-Smit, Christian. Leyendo la historia con una mirada constructivista. En: Relaciones Internacionales, Núm. 20, junio de 2012, GERI - UAM.

Wendt, Alexander. Anarchy is what Stakes Make of it: The Social Construction of Power Politics. En: International Organization, Vol. 46, N 2 (Spring, 1992), pp. 391-425.

Wendt, Alexander. Collective Identity Formation and the International State. En: The American Political Science Review, Vol. 88, No. 2. (Jun., 1994), pp. 384-396. 